\title{
EDITORIAL
}

\section{Juntos, avanzamos y crecemos}

\section{Together, we advance and grow}

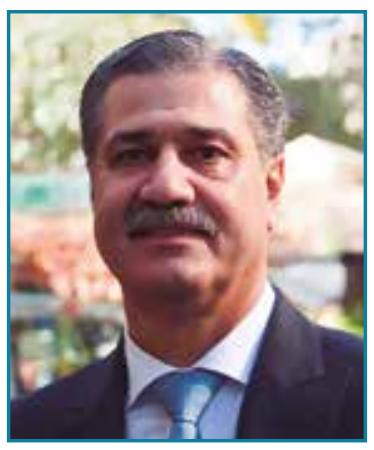

Javier Vaquero Ruipérez Vicepresidente de SETLA
- s para mí un honor dirigirme a todos vosotros por primera vez en este tercer c número de nuestra revista RETLA.

Una revista dedicada y promovida por todos los profesionales sanitarios que nos dedicamos a la Traumatología Laboral y la Patología Laboral en general.

Con solo los dos números anteriores, nos hemos dado cuenta de que sí, que efectivamente el reto, la ilusión y la incertidumbre inicial se van haciendo realidad y estamos comprobando que vamos creciendo y cada vez recibimos más artículos y más trabajos para publicar, lo que demuestra el interés que ha suscitado nuestra revista y el nivel que esperamos alcanzar dentro de la comunidad científica.

Para vosotros, socios o no, es bueno publicar en una revista de prestigio y ese es uno de nuestros objetivos, pero no menos importante es ser fieles a nuestra vocación sanitaria y ser generosos en dar conocer, aportar y enseñar nuestras experiencias y conocimientos para que otros se beneficien de estas experiencias y de estos conocimientos, y ello repercuta en hacer una mejor medicina, unos mejores tratamientos, de mayor calidad y mayor nivel, y que sean realmente nuestros pacientes los que se beneficien de ello.

Así que me dirijo todos los que tengáis algo que aportar y enseñar, os animo a que lo deis a conocer y enviéis vuestros trabajos a nuestra editorial -en la página web de nuestra sociedad os indicamos cómo hacerlo-, para que, una vez pasados los filtros correspondientes de calidad científica, lo podamos publicar.

Como dije al principio, es el tercer número de una revista que nació hace un año pero que se fraguó un tiempo antes, en la anterior presidencia, hasta ver la luz en 2018. 
Como es la primera vez que me dirijo a vosotros, en mi calidad de vicepresidente de la SETLA, no quiero dejar pasar la ocasión de agradecer a todas las personas que han hecho posible que la revista RETLA sea una realidad y que haya nacido con tanta fuerza.

Al Dr. Luis García-Lomas por ser el verdadero impulsor de la revista durante su presidencia de la SETLA, a nuestro Comité Editorial por su tiempo, trabajo, esfuerzo y tesón, y en especial al Dr. Juan Antonio Aguilera y al Dr. Eduardo Sánchez Alepuz como cabezas visibles de la revista RETLA. Por último, a nuestro actual presidente, el Dr. Ángel García Berlinches, que ha sido el verdadero artífice que, por su empeño y dedicación, ha conseguido que por fin saliera a la luz el primer número durante su mandato, en mayo de 2018.

A todos ellos nuestra felicitación, gratitud y admiración.

Y a todos vosotros, os hacemos llegar este nuevo número de la revista RETLA de un gran contenido científico y, de nuevo, os animamos a publicar en la RETLA.

\section{Javier Vaquero Ruipérez}

Vicepresidente de SETLA 